\title{
Using Photovoice to Explore Teenagers' Public Transit Experiences in a Suburban City
}

\author{
Haifa Alarasi ${ }^{1}$ (1), Ron Buliung ${ }^{2}$ (1) \\ ${ }^{1}$ Department of Geography and Planning, University of Toronto, ${ }^{2}$ Department of Geography, Geomatics and Environment, University of Toronto Mississauga \\ Keywords: teenagers, public transit, photovoice, suburban, active travel \\ https://doi.org/10.32866/001c.28117
}

Findings

For many children, the transition to adolescence coincides with the expansion of everyday activities with teenagers taking up transit use to facilitate greater independent mobility and spatial exploration. This paper describes a photovoice exploration of public transit travel of 28 teenagers, 13 to 19 years of age, in Mississauga, Canada. The recorded experiences are grouped under four themes: access; safety; comfort and flexibility; and activity stacking. Findings may offer insights into local transport policies aimed at improving level of service for teenagers and other patrons including reduced group fares, design improvements, and onboard Wi-Fi connectivity.

\section{QUESTIONS}

The transport experiences and travel patterns of children and teenagers remain relatively understudied, when compared with adult-centred research. Although research points to the rise of children's car-captivity since the turn of the $20^{\text {th }}$ century (McDonald et al. 2011; Buliung, Mitra, and Faulkner 2009), this story is far from universal. Teenagers specifically shift towards unsupervised transit mobility in their after-school and non-school trips (Cain 2006). However, issues around limited accessibility; lack of affordability; concerns around cleanliness; lack of information; and safety have shown to impact public transit travel (Clifton 2003). Considering the potential this mode holds in increasing independent mobility, a better understanding of the perceived experiences of teenagers' public transit trips is needed to identify barriers and opportunities to promoting their ridership. This paper contributes to this research gap, through a qualitative exploration of public transit use among new immigrant teenagers in one of Canada's large suburban cities, Mississauga, Ontario.

\section{METHODS}

Our fieldwork involved 28 participants recruited from four of Mississauga's community centers (Table 1$)$. All participants resided in the city for seven years or less and identified as members of ethnic minority groups. We employed photovoice, a method utilizing photographs taken by research subjects to better understand their experiences (Wang and Burris 1997). All participants were asked to use their smart phones to take four photos of things they liked and disliked in their everyday journeys. Semi-structured interviews were then held with each participant to discuss their daily travel. The photos were used during interviews to elicit discussion about participants' travel experiences. The interviews were transcribed and coded in Nvivo. Structural coding was 
Table 1. Participant's Attributes

\begin{tabular}{|c|c|c|c|c|c|c|}
\hline \multirow{2}{*}{ Gender (self-identified) } & \multicolumn{2}{|c|}{ Age Group } & \multicolumn{2}{c|}{ No. of Siblings } & \multicolumn{3}{c|}{ No. of Working parents } \\
\cline { 2 - 7 } & $13-15 \mathrm{yrs}$ & $16-20 \mathrm{yrs}$ & $\geq 3$ & $\leq 3$ & 1 & 2 \\
\hline Female & 8 & 4 & 8 & 4 & 7 & 5 \\
\hline Male & 5 & 11 & 10 & 6 & 15 & 1 \\
\hline
\end{tabular}

initially done to retrieve experiences related to public transit trips, followed by open coding using participants' own terms to guide the construction of codes. The generated codes were then thematically sorted and relationally linked.

\section{FINDINGS}

Participants utilized public transit for multiple trip purposes including school and non-school destinations (i.e., home, work, social/recreational, shopping). Focusing primarily on participant's experiences of transit use that had a social or material quality, we report here on four main themes: access; safety; comfort and flexibility; and activity stacking.

\section{Access}

Participants described long walking paths, multiple transfers, unreliable scheduling, and waiting as troubling aspects of public transit (Figure 1A). Although a reduced fare for students is offered, most mentioned fare price as a barrier pushing them to alternative modes, depending on travel distance. Alternatives included: getting a car ride with parents and/or friends, biking, or walking with friends (Figure 1B). Fare price also impacted travel planning, several participants discussed limiting their time at their destination to two hours - i.e. the maximum allotted time for free transfer. Some participants mentioned how transit extended their access to new experiences and new places outside of their neighbourhoods. The lack of wayfinding data, especially for participants without data plans, appeared to result in some teens opting for non-active modes or a reduced travel range.

\section{Safety}

Discussions about safety were age and gender based, focused on parent and participant risk perceptions, and varied by time of day. Social safety risks were more prominent than traffic safety concerns (e.g., unsafe intersection crossings, or absence of sidewalks). Participants who self-identified as female described being anxious about strangers and fear of harassment on the bus (Figure $1 \mathrm{C}$ ). Younger participants told of not being allowed to travel outside their immediate neighbourhood without an adult companion. Most participants were only allowed to take the bus before dark to manage their own and their parents' risk perceptions. In the few cases where older participants travelled after dark, they preferred taking familiar routes that ran through main streets (Figure 1D). Participants cited travelling with others (e.g., friends, siblings) as 


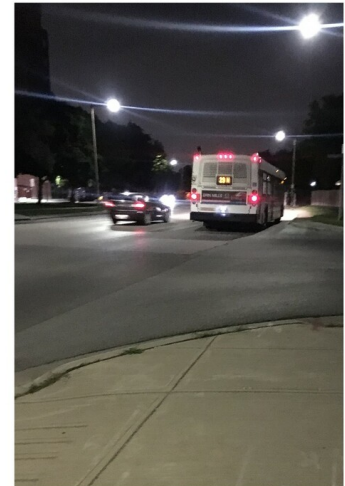

I just didn't like missing the bus. I have to pay, I have to wait, um, if it's hot outside, I'm going to probably sweat and then the bus rides might be late or it'll be too long than usual, stuff like that.

(A) Lama (female, 17)

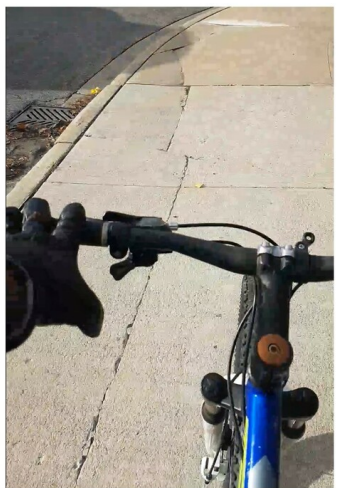

It's faster than walking. Because I can't get dropped off. My dad goes to work and I have a second period. So I can either walk or bike or use my bus card and that's a waste of money. So If it's cold, I wear my gloves and bike.

(B) Dany (male, 17)

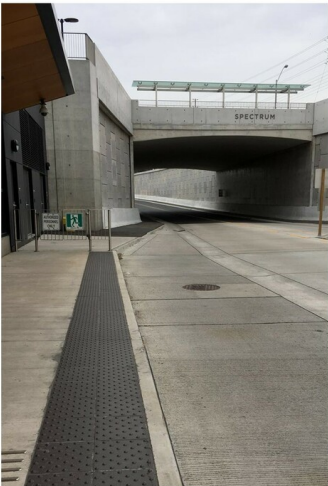

There was a drunk man and he got on the bus, and he was saying things to us. We had to move our seats to the front because we were laughing loudly. We had to switch buses here because it was just us and him and it was kind of creepy.

(C) Sara (female, 16)

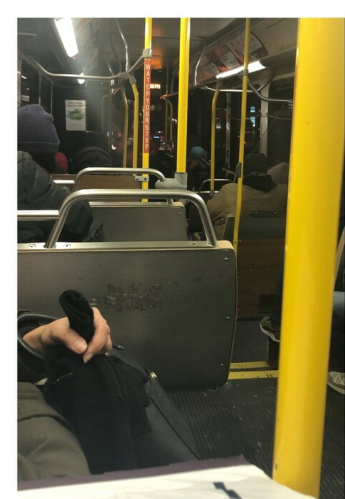

This is on my way back from work. That's why it's at night. I know all the stops so I always just go and sit in the back.

D Roni (male, 18)

Figure 1. Photovoice Examples (Access and Safety)

a way to manage their parents' anxiety while simultaneously negotiating for independent mobility (i.e. without adults' supervision). This was especially the case for females and younger boys.

\section{Comfort and Flexibility}

Most participants described a preference for taking a bus over other modes because of the flexibility it afforded them in making multiple stops, especially during after-school trips. Comfort, however, was a noted problem. Participants talked about design to protect against inclement weather while waiting (Figure $\underline{2 \mathrm{~A}}$ ). Others discussed the negative sensory experiences of crowded buses, loud noises, bad smells, and general problems with cleanliness (Figure 2B). Tactics were applied to re-imagine comfort within the context of design limitations including avoiding certain interior spaces of the bus and waiting longer for less crowded vehicles. Female participants commented on the design and comfort of bus seats especially when compared to regional transit trains.

\section{Activity Stacking}

We define activity stacking as engaging in multiple activities while in the process of moving as a passenger. There is a thread of largely adult focused transport research dedicated to looking at what people do while travelling (Ohmori and Harata 2008; Gripsrud and Hjorthol 2012). We found that almost everyone reported engaging in multiple activities depending on the destination, commute time, company, and time of day. Leisure trips were times for conversations with friends, or a time to disconnect and listen to music 


\section{Photovoice Examples - (Comfort and Flexibility and Activity Stacking)}

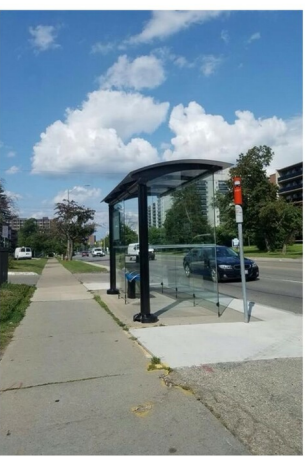

I don't like this bus stop. I just don't like waiting for busses. I don't like sitting there because it gets too hot.

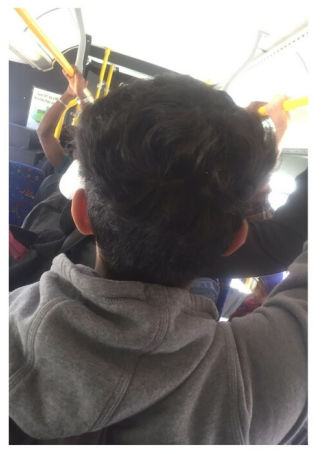

It is always so crowded. I hate it! And there was a seat that was open because the guy sitting next to smelled really bad.

(B) Zain (male, 16)

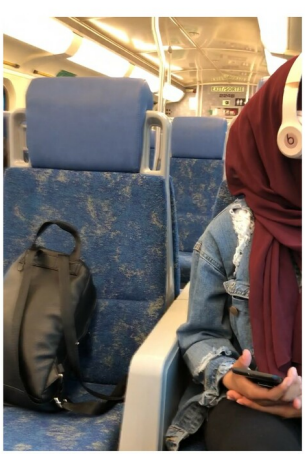

This is just my friend on the regional train. You have your own space, and it goes so fast. She is listening to music. We usually listen to our own things if we are listen to our own things if we are
not talking.

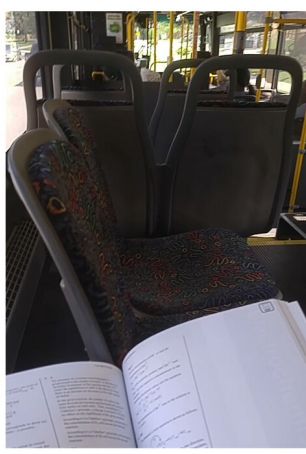

I was going to the central station. So I had a book this time. This is a physics book that my mom brought me to prepare. It was a direct bus so it wasn't that long. If it is a longer bus then I will read more or watch shows.

(D) Basem (male, 17)

Figure 2. Photovoice Examples (Flexibility and Comfort and Activity Stacking)

and catch- up with their social media (Figure 2C). While morning commutes were either a productive time for studying and reading or a time to rest, sleep, daydream (Figure 2D).

Our study suggests minor policy changes that could improve how teenagers perceive the quality of their experience while using public transit. For example, an introduction of a reduced group fare could increase accessibility for many teenagers who prefer travelling in groups. Introducing design improvements for bus stations with heating/cooling shelters is also encouraged. Moreover, introduction of free Wi-Fi in stations and buses would allow for live schedulechecking and wayfinding. This kind of service would facilitate a range of activities while on the move. 


\section{REFERENCES}

Buliung, Ron N, Raktim Mitra, and Guy Faulkner. 2009. "Active School Transportation in the Greater Toronto Area, Canada: An Exploration of Trends in Space and Time (1986-2006).” Preventive Medicine 48 (6): 507-12.

Cain, Alasdair. 2006. "Teenage Mobility in the United States: Issues and Opportunities for Promoting Public Transit.” Transportation Research Record 1971 (1): 140-48.

Clifton, Kelly. 2003. "Independent Mobility among Teenagers: Exploration of Travel to after-School Activities." Transportation Research Record:Journal of the Transportation Research Board, no. 1854: 74-80.

Gripsrud, Mattias, and Randi Hjorthol. 2012. "Working on the Train: From 'Dead Time'to Productive and Vital Time." Transportation 39 (5): 941-56.

McDonald, Noreen C, Austin L Brown, Lauren M Marchetti, and Margo S Pedroso. 2011. "US School Travel, 2009: An Assessment of Trends.” American Journal of Preventative Medicine 41 (2): 146-51.

Ohmori, Nobuaki, and Noboru Harata. 2008. "How Different Are Activities While Commuting by Train? A Case in Tokyo." Tijdschrift Voor Economische En Sociale Geografie 99 (5): 547-61.

Wang, Caroline, and Mary Ann Burris. 1997. "Photovoice: Concept, Methodology, and Use for Participatory Needs Assessment.” Health Education Eं Behavior 24 (3): 369-87. 


\section{SUPPLEMENTARY MATERIALS}

\section{Supplemental Information}

Download: https://findingspress.org/article/28117-using-photovoice-to-explore-teenagers-publictransit-experiences-in-a-suburban-city/attachment/70589.pdf 